Dictadura, democracia y clase obrera: los trabajadores ante el retorno al régimen constitucional al norte de Chubut Gonzalo PÉREZ ÁLVAREZ

Avances del Cesor, Año XII, V. XII, No 12, Primer semestre 2015, pp. 71-88.

ISSN 1514-3899 / ISSNe 2422-6580 - http://web2.rosario-conicet.gov.ar/ojs/index.php/AvancesCesor/index

\title{
Dictadura, democracia y clase obrera: los trabajadores ante el retorno al régimen constitucional en el noreste de Chubut
}

\author{
Dictatorship, democracy and working class. \\ Workers facing the return of constitutional \\ regime in northeastern Chubut
}

\author{
Gonzalo Pérez Álvarez \\ Consejo Nacional de Investigaciones Científicas y Técnicas \\ Universidad Nacional de la Patagonia Sede Trelew \\ (Argentina) \\ gperezalvarez@gmail.com \\ "La derrota tiene algo positivo, nunca es definitiva. \\ En cambio la victoria tiene algo negativo, jamás es definitiva" \\ José Saramago
}

\section{Resumen}

Nos interesa analizar una problemática de la historia reciente de Argentina: la situación que se plantea, una vez finalizada la última dictadura cívico-militar, para las organizaciones obreras, sus formas de lucha y su participación política y/o sindical. Se ha desarrollado un debate a nivel nacional, acerca de si esta dictadura generó una derrota que impidió a los trabajadores sostener formas de organización y lucha que hicieran posible la consecución de sus intereses. La mayoría de las investigaciones coinciden en que la clase obrera inició el régimen constitucional en un marco de gran debilidad, producto de esa derrota.

Sin embargo, ésta no es la única mirada. Otras perspectivas sostienen que la dictadura no significó una derrota para el conjunto de los trabajadores sino que la misma se habría plasmado con la hegemonía del 
neoliberalismo, al iniciarse la década del '90. En esta visión el retorno al régimen constitucional encontró a una clase obrera dinámica que aprovechó las libertades democráticas para intensificar su actividad.

Aportamos a este debate desde un caso complejo. Observar esta porción de la Patagonia argentina implica pensar en una región de continua migración, con una clase obrera que carecía de tradiciones en común. Allí la dictadura no parece haber atacado las experiencias previas de esta clase, que estaba dando sus primeros pasos de organización. Asimismo intentamos observar cómo los trabajadores se relacionaban con la "democracia" y cuáles eran las posibilidades de acción que este régimen político les permitía.

Palabras Clave: Dictadura - Democracia - Clase obrera

\begin{abstract}
We are interested in analyzing a problem of the recent history of Argentina: the situation faced by worker organizations and their forms of political and union participation and struggle, once the last civic-military dictatorship has fallen. There has been a national debate, whether this dictatorship meant such a defeat that prevented workers from holding any form of organization and struggle or not. Most studies agree that at the beginning of the constitutional regime, the working-class was then in a state of great weakness, as a product of that defeat.

Nevertheless, other perspectives hold that the dictatorship did not mean by itself a complete defeat over all working-class. Such would have taken place only when neoliberalism became hegemonic, at the beginning of the ' 90 s. According to this vision, the return to constitutional regime found a dynamic working class, who took advantage of the democratic freedom in order to reinforce their activity.

We reach to this debate from a complex case. This part of Argentine Patagonia is a region of cointinuous migrations, with a working-class that had no traditions in common. The dictatorship there does not seem to have undermined their previous experiences, giving into account that they were just taking their first steps towards organization. In addition, we try to observe how workers related to democracy and which were the possibilities of political action in this context.
\end{abstract}

Key Words: Dictatorship - Democracy - Working-class

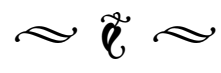

\section{Introducción}

Nos interesa analizar una problemática acerca de la historia de la clase obrera en el pasado reciente de Argentina: la situación que se plantea, una vez finalizada la última dictadura cívico-militar, para los trabajadores, sus organizaciones y sus formas de lucha y participación política y/o sindical.
Sobre este eje se ha desarrollado un debate a nivel nacional, acerca de si esta dictadura generó una profunda derrota que impidió a los trabajadores sostener formas de organización y lucha que hicieran posible la consecución de sus intereses. La mayoría de las investigaciones coincidieron en que la clase obrera afrontó el retorno al régimen constitucional en un marco de gran debilidad, producto de la derrota sufrida por las organizaciones populares. 
Sin embargo, esa no es la única mirada. Otras perspectivas sostienen que la última dictadura no significó una derrota para el conjunto de los trabajadores. Dicha derrota sí se habría plasmado con la hegemonía del neoliberalismo, al iniciarse la década del '90. En esa visión, el retorno al régimen constitucional encontró una clase obrera dinámica que aprovechó las nuevas libertades democráticas para amplificar su actividad.

Pretendemos aportar a esta discusión desde un caso que complejiza la temática. Observar una porción de la Patagonia argentina, específicamente al noreste del Chubut, implica acercarse a una región caracterizada por una continua migración, con una clase obrera "joven" o "en formación" (en especial desde las décadas de 1960 y 1970 por el impulso a los proyectos de "industrialización subsidiada"1).

\section{E1 debate historiográfico}

Presentamos aquí una síntesis del debate historiográfico en torno a la situación de la clase obrera en Argentina tras la dictadura cívico-militar que culminó en 1983. El mismo es de singular importancia para delimitar criterios de periodización acerca de las luchas obreras en la historia reciente de Argentina, y establecer los ejes para analizar los momentos de cambio cualitativo en la dinámica de los trabajadores.

1. Ver BASUALDO, Victoria; BARRAGÁN, Ivonne y RODRÍGUEZ, Florencia, La clase trabajadora durante la última dictadura militar argentina (1976-1983). Apuntes para una discusión sobre la resistencia obrera, La Plata, 2010, p. 7. Disponible en: <http://www.comisionporlamemoria. org/investigacionyense $\% \mathrm{C} 3 \% \mathrm{~B} 1$ anza/recursosdossieredu. html>
Tomamos como referencia para este apartado al trabajo de Pablo Ghigliani- "La noción de derrota en la historia reciente del movimiento obrero argentino"-, ${ }^{2}$ donde se sintetizan diversas miradas acerca de la situación de la clase obrera en Argentina tras la dictadura, en torno a la intención de repensar el concepto de derrota y los diversos usos que se hacen del mismo en la historiografía. Ghigliani pone en duda que la utilización recurrente de esta noción sugiera un consenso o una perspectiva común, y muestra cómo, tras la utilización del mismo concepto, se esconden distintas interpretaciones sobre el cambio en la correlación de fuerzas sociales que habría plasmado la dictadura. Plantea, además, que hay tres grandes vertientes historiográficas que utilizan el término derrota para explicar la situación de la clase tras la dictadura. $\mathrm{La}$ primera es la que tiende a restringir la derrota observada a que dicho gobierno logró poner fin a "un proceso revolucionario o un proyecto político de transformación social". ${ }^{3}$ El autor ubica en esta línea a Izaguirre, Löbbe, Lorenz, Marín y Sartelli. ${ }^{4}$ En segundo término, se señala la concepción que destaca la existencia de una derrota de la clase como tal, que se expresa en cuestiones materiales: la pérdida de conquistas laborales $y$ un

2. GHIGLIANI, Pablo, "La noción de derrota en la historia reciente del movimiento obrero argentino", ponencia presentada en VJornadas de Sociología de la UNLP y I Encuentro Latinoamericano de Metodología de las Ciencias Sociales, UNLP, 2008. Disponible en <http:// www.aacademica.com/000-096/570.pdf>

\section{Ibídem.}

4. Consideramos que la perspectiva de Izaguirre y Marín no concuerda con esta lectura, ya que ambos proponen una mirada más amplia del proceso, que tiende a hacer observable la interrelación de fuerzas objetivas y políticas, comprendiendo la derrota en un sentido integral. Ver MARÍN, Juan C., Los hechos armados: Un ejercicio posible; CICSO, Buenos Aires, 1984; IZAGUIRRE, Inés, Los desaparecidos: recuperación de una identidad expropiada. CEAL, Buenos Aires, 1994. 
importante retroceso de la participación de los trabajadores en el ingreso nacional. Esta visión (que para Ghigliani desarrollan Werner y Aguirre) se termina limitando al análisis del aniquilamiento de las expresiones de izquierda. Por último, se destaca el enfoque de Abós, Campione, Gilly y Horowicz, que el autor propone como más fundamentado. El mismo sostiene que “...subrayando también la existencia de una derrota histórica de la clase obrera, incluye entre los perdedores a sus direcciones reformistas, esto es, a la dirigencia sindical y al peronismo histórico". ${ }^{5}$

Otros investigadores han recuperado la acción de la clase obrera durante la dictadura y su capacidad de convertirse en antagonista de la misma, aún en condiciones de gran debilidad. Desde esa perspectiva, autores como Pozzi, Bitrán y Schneider han rechazado el uso de la noción de derrota. Discuten que en los procesos históricos puedan hacerse lecturas de resultados específicos, pensando que toda situación es coyuntural, y lo que hoy puede parecer una derrota, en el largo plazo tal vez aporte elementos para una posterior victoria. Y, específicamente, no consideran que la dictadura haya significado un cambio cualitativo en el proceso, sino que constituyó un paso más en la larga secuencia de pérdida de poder que venían sufriendo los trabajadores en Argentina desde 1955 (cuando se produce el golpe de estado contra el gobierno de Perón). Esto no implica desconocer el asesinato de miles de activistas obreros, y la ruptura de la mayoría de sus organizaciones políticas y sindicales. Pero, para ellos, los obreros supieron resistir a la dictadura y fueron el factor clave en la caída de ese régimen. Pozzi y Schneider sí reconocen una derrota del movimiento obrero entre 1991 y 1993, convergiendo con un consenso historiográfico que señala un cambio cualitativo en los primeros años de la presidencia de Carlos Menem.

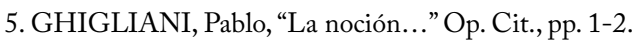
74
Concluimos que se trata de observar a la última dictadura como una profunda reestructuración capitalista. Partir de esa perspectiva nos hace percibir “...que la política laboral de la dictadura no se detuvo en el aniquilamiento de las corrientes revolucionarias sino que estuvo dirigida a llevar lo más lejos posible la desorganización de la clase para facilitar el éxito del proceso de acumulación”. 6

Los investigadores que trabajan desde el PIMSA $^{7}$ no son analizados en el artículo de Ghigliani. Aunque en general no han hecho referencia al concepto de "derrota", han indagado acerca de los momentos de quiebre en las relaciones de fuerzas sociales. En varios trabajos de este programa ${ }^{8}$ han desarrollado dichos debates.

En ese sentido, la discusión sobre el uso de la noción de derrota nos parece relevante pero no definitoria. No importa tanto el uso del término sino comprender si estamos ante cambios cualitativos en la correlación de fuerzas sociales. Es evidente que, durante la dictadura, se produjo una reestructuración de la sociedad que tuvo como principal perjudicada a la clase obrera en su conjunto. Pero es fundamental especificar cómo se expresa esa transformación en las distintas regiones del país, donde las relaciones de fuerzas nacionales

6. Ídem, p. 11.

7. Programa de Investigación sobre el Movimiento de la Sociedad Argentina.

8. Entre otros en IÑIGO CARRERA, Nicolás; COTARELO, María; GÓMEZ, Elisabeth. y KINDGARD, Federico, La revuelta. Argentina 1989/90, en PIMSA DT, Buenos Aires, 1995, No 4; IÑIGO CARRERA, Nicolás y PODESTÁ, Jorge, Las nuevas condiciones en la disposición de fuerzas objetivas. $L a$ situación del proletariado, en PIMSA DT, Buenos Aires, 1997, № 5. 
se complejizan y articulan con las relaciones de fuerzas locales. 9

Este artículo se enmarca en un contexto de producción historiográfica de diversos investigadores que vienen analizando estas dinámicas en contextos regionales. Nos referimos a trabajos de Barragán, Esponda, Bretal, Dicósimo, Carminati, Simonassi, Rodríguez, Lorenz, Gresores y Schneider, entre muchos otros. ${ }^{10}$ Trabajar esta extensa y

9. Como plantea Gramsci, el análisis de las relaciones de fuerzas se complica aún más por las diferentes secciones territoriales dentro de cada país, en cuyo seno se combinan las distintas fuerzas nacionales e internacionales, conformando “...estructuras diferentes y relaciones de fuerzas también diferentes en todos los grados". En GRAMSCI, Antonio, Notas sobre Maquiavelo, sobre la politica y sobre el estado moderno, Nueva Visión, Buenos Aires, 1997, p. 59.

10. Sin pretender una enumeración exhaustiva, ni de autores ni de trabajos, citamos algunas contribuciones que consideramos relevantes: BARRAGÁN, Ivonne, "Acción obrera durante la última dictadura militar, la represión en una empresa estatal. Astillero Río Santiago (1974-1984)", en BASUALDO, Victoria (coordinadora) La clase trabajadora argentina en el Siglo $X X$ : Experiencia de lucha y organización. Cara o Ceca, Buenos Aires, 2011; BASUALDO, Victoria, "El lugar otorgado a las transformaciones económicas y a la clase trabajadora en la historiografía revisionista reciente sobre la última dictadura militar", en Actas IV Seminario Internacional Politicas De La Memoria, Buenos Aires, 2011. Disponible en: <http://conti.derhuman.jus.gov. ar /2011/10/seminario.shtml>; BRETAL, Eleonora, Experiencias de organización y lucha sindical en el Gran La Plata: El caso de Petroquimica Sudamericana, 19691973, UNLP. FAHCE, La Plata 2008. Disponible en: $<$ http://www.memoria.fahce.unlp.edu.ar/tesis/te.501/ te.501.pdf >; CARMINATI, Andrés, "El fin del reflujo. Primera huelga general durante la última dictadura. Un estudio desde el Gran Rosario de las luchas obreras durante el año 1979", ponencia presentada en XIV Jornadas Interescuelas de Historia, UNCu. Mendoza, 2013; DICÓSIMO, Daniel, "Indisciplina y consentimiento en la industria bonaerense durante la última dictadura militar. Los casos de Loma Negra Barker y Metalúrgica Tandil”, en Sociohistórica, FAHCE, UNLP, La Plata, 2008, No 23, pp. 13-38; ESPONDA, María Alejandra, “De la amplia producción amerita una investigación específica, que debiera buscar un camino de síntesis entre estas miradas para ir perfilando una mucho más compleja perspectiva nacional. Las conclusiones de este artículo dialogan y retoman aportes de dichas investigaciones.

\section{Algunos elementos previos}

Trabajamos con un archivo basado en el registro de publicaciones periodísticas de la región para armar la columna vertebral del relato. Además, hemos consultado archivos gubernamentales y fuentes menos exploradas, como entrevistas a trabajadores, documentos partidarios, actas de sindicatos, etc. $\mathrm{Ha}$ sido clave, el aporte de las entrevistas a trabajadores que participaron de estos procesos. $\mathrm{La}$ construcción de fuentes orales nos brinda parte del significado que tuvieron estos hechos para los sujetos que los desarrollaron. En

dictadura a los '90, y de los '90 a la dictadura. Legados e impactos sobre la clase trabajadora y sus posibilidades de organización en el lugar de trabajo", en Actas IV Seminario Internacional Políticas De La Memoria, Buenos Aires, 2011; LORENZ, Federico, Los zapatos de Carlito. Una bistoria de los trabajadores navales de Tigre en la década del 70, Editorial Norma, Buenos Aires, 2007; GRESORES, Gabriela, "Conflictos obreros en la industria frigorífica bajo la dictadura militar: La huelga larga de Swift de Berisso", en Revista Ciclos, Buenos Aires, 2001, Año XI, V. IX, No 22; RODRÍGUEZ, Florencia, "La política represiva contra los trabajadores. Abordaje comparativo de los casos de Mercedes Benz Argentina y Propulsora Siderúrgica"en Actas IV Seminario Internacional Políticas De La Memoria, Buenos Aires, 2011; SCHNEIDER, Alejandro, “Ladran Sancho...' Dictadura y clase obrera en la zona norte del Gran Buenos Aires" en CAMARERO, Hernán, POZZI, Pablo y SCHNEIDER, Alejandro, De la Revolución Libertadora al Menemismo, Imago Mundi, Argentina, 2000; SIMONASSI, Silvia, “'A trabajar y muzzarella’ Prácticas y políticas de disciplinamiento laboral en la industria metalúrgica de Rosario 19741983”, en Historia Regional, ISP No3, Villa Constitución, 2007 , No 25 , pp. $57-82$. 
cambio, las fuentes escritas suelen ocultarnos aspectos claves de la conflictividad social: particularmente dicen poco sobre muchas formas de resistencia, necesariamente subterráneas.

En términos metodológicos recuperamos el enfoque gramsciano que postula una aproximación "molecular" al proceso. Siguiendo su "Apuntes sobre la historia de las clases subalternas...", Gramsci formula las dificultades que se presentan para investigar la actividad de los trabajadores y la formación de sus organizaciones. El accionar autónomo de la clase tiende a ser borrado de la historia por los grupos dominantes, que en general logran derrotar los proyectos de organización de los grupos subalternos. Es por ello, que los investigadores que buscamos comprender esas dinámicas debemos partir de ese “... proceso molecular, minucioso, de análisis extremo, capilar... este lento trabajo del cual nace una voluntad colectiva con cierto grado de homogeneidad, con el grado necesario y suficiente para determinar una acción coordinada y simultánea en el tiempo y en el espacio geográfico en el que se verifica el hecho histórico". ${ }^{11}$

La necesidad de un mínimo contexto histórico, nos lleva a hacer referencia al impulso que desde el Estado Nacional se dio a la instalación de "polos de desarrollo" en la Patagonia argentina, para promover la llegada de migrantes a una región poco poblada $\mathrm{y}$ con escasas perspectivas de crecimiento económico. ${ }^{12}$ Esta política se proponía la creación de centros industriales que irradiarían el "progreso" hacia las regiones cercanas, con

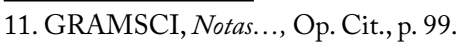

12. Para un mayor desarrollo ver PÉREZ ÁLVAREZ, Gonzalo, "Lucha y memoria obrera en el noreste del Chubut. Una aproximación desde la fábrica Modecraft 1990-1991", en Historia Antropología y Fuentes Orales, Barcelona, 2009, № 41, pp. 25-48. una incidencia clave de la Doctrina de Seguridad Nacional, aspecto reflejado en la declamada intención de poblar la Patagonia en tanto región estratégica por sus recursos naturales. ${ }^{13}$ Un hito en el programa "desarrollista"14 está registrado en el decreto-ley 10.991/56 de la autodenominada "revolución libertadora", ${ }^{15}$ que eximió de impuestos a las importaciones al sur del paralelo $42^{\circ}$. Por ser la región más cercana al límite norte, la promoción se concentró en la zona noreste de Chubut. Desde la década del '60, se impulsó la instalación de fábricas que procesaban fibras textiles sintéticas. En 1971, se creó el Parque Industrial de Trelew y hacia 1973 la rama textil de Chubut ocupaba el segundo puesto nacional en varios rubros del sector. ${ }^{16}$ También en 1971, se adjudicó a ALUAR (Aluminio Argentino S.A.) la construcción de una planta productora de aluminio primario, a instalarse en Puerto Madryn. En ambos casos, la inversión fundamental fue aportada por el Estado, realizando una enorme transferencia de fondos públicos a empresas privadas. A partir del desarrollo industrial y la generación de puestos de trabajo, se incentivó la llegada

13.GATICA, Mónica, ¿̇Exilio, migración, destierro? Los trabajadores chilenos que se asentaron en el NE de Chubut a partir de septiembre de 1973, Tesis doctoral, FHACEUNLP, La Plata, 2010.

14. Para su aplicación en Patagonia, ver PERREN, Joaquín y PEREZ ÁLVAREZ, Gonzalo, "Las “nuevas” provincias como problema historiográfico. Una aproximación a los casos patagónicos (1958-1991)”, en Revista Pasado Por-Venir Chubut, 2011, No 5, pp. 75-101.

15. Dictadura que había derrocado en 1955 al gobierno constitucional de Juan Domingo Perón.

16.Aunque la producción era mucho menor que la del área metropolitana: Chubut ocupaba el segundo puesto en producción de medias (15\%, contra un $83 \%$ del área metropolitana), tejido de punto ( $11 \%$ contra un $81 \%$ ) e hilado de fibras textiles $(6,4 \%$ contra un $76 \%)$. Datos de CIMILLO, Elsa, Bloque textil: dinámica en la provincia del Chubut. 1973-1984, CFI-CEPAL, Buenos Aires, 1985, pp.12-13. 
de migrantes, que impactó en la escasa población que hasta entonces habitaba en la región. Gran parte de aquellos se movilizaron desde el interior de la provincia de Chubut en busca de una mejor situación económica. Eran habitantes de la zona rural, que abandonaban sus tierras ante la imposibilidad de trabajarlas debido a la falta de capital y al avance de los latifundios que desplazaba a los pequeños productores. ${ }^{17}$ También llegaron migrantes del norte argentino ${ }^{18}$ y de países limítrofes. ${ }^{19}$

\section{Una clase en formación}

Una de nuestras hipótesis sostiene que durante los primeros años de laindustrialización subsidiada se conformó una nueva clase obrera en la región, producto del arribo de diversos contingentes migrantes. Esta clase obrera, heterogénea y que en muchos casos no tenía experiencia $^{20}$ de trabajo fabril o de vida urbana, se encontró con un contexto de pleno empleo y con la posibilidad de ir mejorando sus condiciones de vida a partir de una oferta

17. Ver TRONCOSO, Ana María, El proyecto civilizador entre las prácticas sociales y las estrategias de resistencia, de negociación y de apropiación en la meseta norte chubutense (1900-1970), Tesis de Doctorado en Historia, UNCPBA, Tandil, 2011.

18. Nos referimos a habitantes de las provincias ubicadas al norte del Río Colorado (ubicado en la provincia de Río Negro). El Río Colorado es considerado el límite norte de la Patagonia argentina.

19. Ver las investigaciones de GATICA, Mónica, ¿̇xilio, migración o destierro?..., Op. Cit., y de HUGHES, Judith, OWEN, Olga y SASSONE, Susana, “Trayectorias migratorias en espacios rurales: bolivianos en el Valle Inferior del Río Chubut", en Contribuciones Cientificas GEA, Buenos Aires, 2007, V. XIX.

20. La utilización del concepto remite a THOMPSON, Edward. P, La formación de la clase obrera en Inglaterra, Crítica, Barcelona, 1989; y al despliegue que realiza del mismo a lo largo de su trabajo. dinámica y bien remunerada de empleo.

E1 desarrollo de esta industrialización subsidiada planteó la necesaria construcción de una clase obrera en la región, que trabajase en las fábricas que se instalaban y en las actividades satélites que se iban conformando. Consideramos que esta "nueva" clase no tuvo lazos fuertes con las experiencias y tradiciones que los trabajadores habían desarrollado en la región; esto no implica que hasta allí no hubiera conflictos u organización obrera, ${ }^{21}$ pero sí que la clase que se conformó no parece haber construido vínculos de importancia con esa experiencia previa. El rasgo central sería el de su escasa experiencia política y sindical, falta de tradiciones en común y ausencia de experiencia colectiva en tanto trabajadores industriales y/o urbanos. Esto explicaría en parte el bajo nivel de conflictividad ${ }^{22}$ y la identificación de intereses entre estos trabajadores y los grupos dominantes del proyecto de industrialización subsidiada.

Distintas empresas que se instalaron al abrigo de la industrialización subsidiada desarrollaron un proyecto similar al que reseñan Escobedo y Prospitti ${ }^{23}$ al analizar la

21. Ver GATICA, Mónica y PÉREZ ÁLVAREZ, Gonzalo, "No solamente pasaba el viento: sindicatos, huelgas, boicots, cortes de vías y lucha política en los primeros pasos del movimiento obrero en el noreste del Chubut (1917-1922)", en ARIAS BUCCIARELLI, Mario (director) Diez territorios Nacionales y catorce provincias, Argentina, 1860/1950, Prometeo, Buenos Aires, 2012, pp. 187-214.

22. Especialmente en comparación con lo que acontece durante este período en los centros industriales del país. Ver la hipótesis de que estos proyectos buscaban "despromover" el trabajo industrial en las áreas tradicionales, para descomprimir la conflictividad existente, en SCHVARZER, Jorge, Promoción industrial en Argentina. Características, evolución y resultados. Documentos del CISEA, Buenos Aires, 1986.

23. ESCOBEDO, Martín y PROSPITTI, Agustín, "Estudio de las prácticas sindicales de los trabajadores 
creación del colectivo obrero de Somisa: "La mano de obra empleada combinaba juventud, ausencia de tradición sindical, altos ingresos y estabilidad en el trabajo". Se intentaba conformar una "fuerza de trabajo que estuviera en sintonía con las necesidades de los nuevos sectores industriales en desarrollo, y que no arrastrara los elementos de conflictividad que se hacían evidentes en las ciudades industriales más antiguas". ${ }^{24}$

Este comportamiento es observable para el caso de la mayor empresa instalada en la región, la productora de aluminio primario ALUAR, ${ }^{25}$ que seleccionó la mayoría de su personal entre trabajadores de origen rural, a los cuales aseguraron vivienda, la mudanza hasta Puerto Madryn y un trabajo bien remunerado. Pretendían asegurar la "fidelidad" de estos obreros, que no traían experiencias significativas sobre organización gremial o política. De esta manera lo recuerda Fernando:26 "ALUAR se caracterizó siempre por traer gente de campo. En el ' 70 y pico, cuando empieza, no va a buscar en Buenos Aires obreros capacitados ni nada, sino que va a buscar gente a las provincias: La Pampa, Mendoza, gente que no tenía

petroquímicos y metalúrgicos en sur santafesino", en Historia Regional, ISP No3, Villa Constitución, 2006, № 24, pp. 47-64.

24. Ídem, p. 55.

25. ALUAR es una gran empresa de capital concentrado, siendo la única productora de aluminio primario en Argentina. Esto la diferencia claramente del resto de las fábricas instaladas en la región, caracterizadas por una escasa maquinización y por ser fábricas pequeñas a medianas.

26. Fernando, entrevista realizada el $2 / 5 / 2008$. Es un cuadro técnico, llega a mediados de los ' 80 desde La Plata y no trae experiencia de militancia previa. historia sindical". Otro entrevistado, Héctor, ${ }^{27}$ rememora que: “...el operario común era casi toda gente de campo, la mayoría sin ninguna experiencia fabril. No así los que tenían su especialidad como electricista, mecánicos y cosas así, que ya venían con su experiencia en fábricas. Y ALUAR para mí, y esto siempre lo comentamos, lo que buscaba era un obrero sin experiencia en fábrica, para poder amoldarlos a su manera".

En el parque textil, no se observa un comportamiento homogéneo dada la presencia de diversas empresas, pero sí es evidente que gran parte de los trabajadores son migrantes sin experiencia sindical y, en muchos casos, sin experiencia de trabajo fabril o vida urbana. Esto en el marco de una fuerte heterogeneidad, como lo destaca Daniel: ${ }^{28}$ "Como cosa más formal teníamos una caracterización que era que en el parque industrial la mayoría venía del minifundismo y por lo tanto no tenía tradición proletaria. Pero en realidad cuando veías bien había de todas partes". ${ }^{29}$ Daniel era un recién venido de Buenos Aires y, además, un recién llegado a la vida fabril: “...tenía 27 años y nunca había trabajado en fábrica. Yo era militante y venía a trabajar de lo que saliera, pero toda la vida había sido vendedor... nunca había trabajado en fábrica, así que para mí fue toda una experiencia". ${ }^{30}$ Una anécdota suya ilustra la complejidad de esa clase en

27. Héctor, entrevista realizada el 9/5/2008. Fue integrante de la lista opositora al oficialismo en la UOM. Era trabajador rural antes de incorporarse a ALUAR.

28. Daniel, entrevista realizada el 4/4/2012 en la sede Trelew de la Universidad. Militante del Movimiento Al Socialismo (MAS), llegó a la región a principios de los ' 80 . Fue miembro de la Comisión Interna de Textil Punilla, fábrica de unos 300 trabajadores, productora de telas.

29. Daniel, entrevista..., Op. Cit.

30. Ibídem. 
formación: “...el primer asado que como, lo como el 20 de diciembre, una cosa así, antes de las fiestas. Y estoy sentado al lado del sereno de la fábrica, que era un compañero aborigen. Entonces al tercer vino el loco se paró y empezó a cantar un lamento indio. Y yo cuando lo escuché no entendía nada... Cuando termina de cantar lo abrazo y le digo 'para que nos vayamos conociendo Ancamil, yo al personaje de la historia argentina que más aborrezco es al general Roca'. Y salta uno, laburante eh, 'si no fuera por Roca vos no estarías comiendo un asado en la Patagonia". ${ }^{31}$ La contraposición de diversas historias es evidente y esas experiencias se expresaban también en diferentes posturas ideológicas. La matriz del proyecto de ocupación de Patagonia por parte del Estado argentino fue una parte clave del proceso. Esta perspectiva planteaba la existencia de una comunidad de intereses entre obreros y patrones de la región, cuyo objetivo era asegurar el desarrollo de la Patagonia. Dicha posición se reforzaba con la idea de mantener la "paz social", para no poner en riesgo la promoción industrial que el Estado Nacional asignaba a la región.

El discurso era poderoso, justamente porque no era sólo un discurso y se asentaba en elementos objetivos. La subsistencia de las industrias en la región dependía de los aportes estatales, que ya al comenzar la década del ' 80 empezaron a ser cancelados. Los trabajadores eran conscientes de este problema, y la mayoría desarrollaron los principales conflictos de estos años alrededor de una estrategia que planteaba una alianza con la burguesía con fuertes intereses en la región, ${ }^{32}$ la cual era la que dirigía

31. Ibídem.

32. Nos referimos a una "burguesía con intereses en la región" y no a una "burguesía regional" ya que se trata de empresarios con inversiones en varias ramas económicas y diversas regiones del país, que en su gran mayoría no viven en Chubut. Ver PÉREZ ÁLVAREZ, Gonzalo, "Pioneros, Patrióticos y Patagónicos. El discurso de la el proceso. Dicha alianza tenía como programa la "defensa de la región", demandando el sostenimiento de los beneficios para los empresarios que invertían en Chubut.

\section{La resistencia durante la dictadura}

Estas características de la clase obrera incidieron en el tipo de conflictividad y organización que los trabajadores desarrollaron. La identificación de parte de sus intereses con los de los dueños de las empresas, la construcción de alianzas con las patronales y sus organizaciones corporativas, y la sintonía en un discurso compartido sobre la necesidad de potenciar el desarrollo de la Patagonia, son elementos claves a lo largo de la historia de esta joven clase obrera. Esto no significa que no hayan existido luchas y conflictos. Pero sí que estos hechos tomaron una coloración particular, que debemos asimilar para comprender la dinámica de la clase y el tipo de conflictividad obrera que se hace presente en el contexto de esta industrialización subsidiada. La clase obrera, que se conforma en lo estructural durante los años ‘ 60 y ‘ 70 , comenzó a desarrollar sus reclamos en un contexto de intensa vigilancia. Quizás por ello se trataba de conflictos de dimensiones reducidas, vinculados a las condiciones de trabajo por planta.

Una síntesis sobre la dinámica de la clase obrera en este período a nivel nacional puede encontrarse en el citado trabajo de Basualdo, Barragán y Rodríguez. ${ }^{33}$ Allí se desarrolla

Unión Industrial Patagónica en su etapa fundacional", en Revista Ciclos, Buenos Aires, en prensa.

33. BASUALDO, Victoria, BARRAGÁN, Ivonne y 
parte de la polémica historiográfica acerca de la actividad de los trabajadores durante la dictadura, postulando las autoras la aquí retomada noción de "resistencia obrera" ${ }^{34}$.

Durante los años de dictadura son escasas las manifestaciones públicas, aunque aún debemos explorar diversas formas de protesta que se desarrollaron. La iniciativa más evidente fue la negativa a trabajar horas extras: hemos relevado este hecho entre los textiles y los trabajadores de ALUAR. La demanda de mejores condiciones de trabajo se realizaba a través de este método, que no contradecía la legalidad pero sí enfrentaba las "costumbres" de la región, donde, en el marco de una industrialización en desarrollo, se hacía necesario el uso intensivo de la todavía escasa fuerza de trabajo disponible. Así cuenta Gerardo $^{35}$ esta medida en ALUAR y la forma en que la empresa enfrentó el reclamo: “...en el '79, en plena dictadura, tuvimos un conflicto que se origina por el tema del cese de las horas extras. Nos negamos a hacer horas extras y pedimos incorporación de personal. Entonces vamos a un paro porque nos obligaban. En verdad no era un paro, nos negábamos nomás a hacer las horas y la empresa nos intima por usos y costumbres y otras cosas. En eso baja uno de los directivos mayores, un hombre que había sido de Fate $^{36}$, y en esa reunión

RODRÍGUEZ, Florencia, La clase trabajadora..., Op. Cit.

34. Ver también FALCÓN, Ricardo, "La resistencia obrera a la dictadura militar. Una reescritura de un texto contemporáneo a los acontecimientos”, en QUIROGA, Hugo y TCACH, César (compiladores) $A$ veinte años del golpe. Con memoria democrática. Homo Sapiens, Rosario, 1996.

35. Gerardo, entrevista realizada el 2 de Mayo de 2008. Arriba a Madryn en 1977, teniendo conocimiento de la actividad sindical por haber sido delegado de una pequeña empresa metalúrgica de Lanas.

36. La mayor parte del capital accionario de ALUAR es propiedad de la familia Madanes, también nos dice, sutilmente, '¿ustedes no saben que esta empresa la manejan las Fuerzas Armadas por intermedio de la Aeronáutica?'” Héctor recuerda situaciones parecidas: "Hubo algún intento de paro en que vinieron a buscar algunos operarios de sectores muy puntuales, y se los llevaron a punta de fusil, de eso me acuerdo, durante la dictadura. Estábamos ahí haciendo una medida de fuerza frente a la planta de aluminio, me acuerdo que llovía o lloviznaba, y se llevaron detenidos a dos o tres compañeros, hubo cosas pesadas, así... eran épocas difíciles".

El negarse a realizar horas extras también fue la forma de protesta que hemos relevado durante la última dictadura en el parque de Trelew. Así lo narra René: “...ya era en principio del 77, estaba el golpe de estado y no nos daban aumento de sueldo. Estaban tan acostumbrados a que hiciéramos las horas extras, por la misma necesidad que teníamos... Había que convencer a los compañeros de que no estábamos haciendo un paro porque en realidad no era un paro... y siempre estaba el rumor de la noticia no confirmada del terror, viste. Estaba el rumor de que a fulano en una fábrica lo echaron con toda su familia, lo dejaron en la frontera y los pacos lo cagaron a palos". 37

Era un reclamo que tenía relación con la

propietaria de la empresa FATE. El uso de la palabra "baja" hace referencia a que ese directivo venía del norte (específicamente de Buenos Aires), siendo una expresión habitual en la región, especialmente entre los trabajadores.

37. René, entrevista realizada el 4 de Julio de 2009. Trabajador textil y militante del Partido Comunista (PC). Es de origen chileno, como un sector importante de la clase obrera de la región. El término "pacos" hace referencia a la policía militarizada de Chile, los "carabineros". Trabajaba en la fábrica textil Huamac, productora de telas y con relevante incidencia en la producción del parque hasta los años' 80 . 
posibilidad de esos trabajadores de disfrutar su vida. En este sentido es claro el testimonio de Miguel: ${ }^{38}$ "En el '83, vine con 19 años de Buenos Aires a trabajar acá, supuestamente a ganar un muy buen sueldo y casa, era el compromiso. No fue tan así, el sueldo era bueno, pero porque no tenías ni tiempo de gastarlo. Te obligaban a trabajar 12 horas, entonces yo llegué en julio... Te podes imaginar ¡julio en Trelew!... entrabas a las 6 de la mañana, salías a las 6 de la tarde, no podías hacer nada, ni veías el sol”.

Otro reclamo relevado (en este caso por Tania Pérez Aguilar) ${ }^{39}$ es un planteo por productividad en la fábrica Supersil. Fue impulsado por trabajadores de origen chileno, quienes además coordinaban el campeonato de fútbol textil, otra manera en la cual los obreros lograban reunirse durante aquellos años. Uno de sus entrevistados, Joel, narra: "Recuerdo que el petitorio fue redactado por Adolfo Pérez Mesa, quien primero llevó el borrador y lo revisamos dos o tres compañeros, luego que lo aprobamos, al día siguiente apareció el original listo para firmar". ${ }^{40}$ Por su parte Adolfo explica: "Creo que al lograr la respuesta positiva a nuestra carta, sentimos un alivio natural,

38. Miguel, entrevista realizada el 15/6/2007 en el café Touring Club. Fue delegado de la fábrica Modecraft, referente de la oposición en la AOT (Asociación Obrera Textil, sindicato que agrupa a los operarios textiles) y militante del Partido Intransigente (PI). Modecraft era una fábrica mediana (200 trabajadores), productora de medias. Tenía gran importancia por contar con una fuerte comisión interna y estar ubicada en la región céntrica de la ciudad, por lo cual sus conflictos se visibilizaban rápidamente.

39. PÉREZ AGUILAR, Tania, Avance de la investigación, Taller V, del Área VI de la Licenciatura en Historia, Facultad de Humanidades y Ciencias Sociales, UNP, sede Trelew, 2002.

40. Entrevista a Joel "Pantera" Sánchez, realizada por Tania Pérez Aguilar en su casa de Trelew, 2001. donde pusimos a prueba un trabajo político que había quedado trunco el 11 de septiembre de 1973. Actuamos en forma coordinada y cada cual tenía un trabajo específico que se magnificó con la actividad deportiva... habíamos constituido la Liga Textil de Fútbol que llegó a mover a unas quince fábricas con más de 1.500 personas en la cancha todos los domingos. En plena dictadura militar, los trabajadores textiles se reunían todos los domingos en torno a una pelota”. ${ }^{41}$ Es más que interesante el vínculo que Adolfo realiza en su testimonio entre el conflicto fabril que ellos dirigieron ya en el exilio, con las luchas que desarrollaron en el Chile de la Unidad Popular. Como afirma Saramago, la derrota nunca es definitiva, así como tampoco lo es la victoria. Esos trabajadores de origen chileno, duramente atacados por la dictadura de Pinochet, lograban volver a poner "a prueba" esa acumulación de fuerzas y experiencias, que venían realizando como clase en su país de origen.

Pero no siempre las acciones culminaban en una victoria. Gatica ${ }^{42}$ relevó el siguiente caso en la fábrica "Dos Muñecos": ${ }^{43}$ “...una vez empecé a reclamar porque las condiciones eran paupérrimas, comíamos encima de las máquinas: hicimos una asamblea, había una delegada pero no podía hacer nada. Hicimos una protesta y vino el viejo y nos dijo que si no nos dábamos cuenta que estaban los militares, que no se podía protestar, y dijo que jal que le

41. Entrevista a Adolfo Pérez Mesa, realizada por Tania Pérez Aguilar en su casa de Trelew, 2001. Ver PÉREZ ÁLVAREZ, Gonzalo, "Juego, resistencia y cultura obrera en la Patagonia Argentina: el fútbol ante contextos represivo", en Revista Nuevo Mundo Mundos Nuevos, Mascipo, 2013.

42. GATICA, Mónica, ¿Exilio, migración o destierro?..., Op. Cit. 2010. p. 186-187.

43. Una de las más importantes plantas fabriles instaladas en Trelew, superó los 500 trabajadores y confeccionaba jeans y otras prendas de vestir. 
gusta se queda y al que no, se va! ...Así que me fui". ${ }^{44}$

Por la presión represiva las acciones se restringieron a aquellas que no trascendían la legalidad, buscando no contradecir el discurso acerca de la coincidencia de intereses entre obreros y patronales de la región. Pese a ello, es evidente que esta clase obrera desarrolló diversas formas de protesta durante la dictadura; hacerlas observables permite profundizar el conocimiento sobre sus características y su proceso de conformación.

La hipótesis que formulamos desde los elementos que hemos recabado es que la clase obrera de la región no sufrió una derrota durante la dictadura, ya que por entonces no existía en el noreste del Chubut una tradición obrera que la dictadura apuntara a destruir. De hecho, es durante ese período cuando se desarrollaron las primeras experiencias significativas de autoorganización, especialmente entre los trabajadores privados, las que se expresaron en los años ' 80 y fueron derrotadas posteriormente. ${ }^{45}$

\section{El regreso al régimen constitucional}

A través de esos procesos, se fue conformando una experiencia colectiva entre los trabajadores y se estructuraron comisiones internas en algunas fábricas textiles y en ALUAR. También en la construcción comenzaron a elegirse delegados

44. Patricia, entrevista realizada por Mónica Gatica, en casa de la entrevistada el 12 de Noviembre de 2008.

45. Ver PÉREZ ÁLVAREZ Gonzalo, Patagonia, conflictividad social y neoliberalismo. El noreste de Chubut (1990-2005), Imago Mundi, Buenos Aires, 2013. con una línea distinta a la del sindicato. ${ }^{46}$ Son esas experiencias de autoorganización las que generan una acumulación de fuerza que se expresó tras el regreso al régimen constitucional. El fin de la dictadura no pareció alumbrar una clase obrera débil y fragmentada. De hecho, se destaca el surgimiento de nuevos agrupamientos y de una mayor dinámica por parte de los trabajadores de la región. Las fuerzas que se habían ido acumulando, y que estaban contenidas en el contexto represivo de la etapa anterior, parecieron liberarse y avanzar en la búsqueda de nuevas conquistas y/o de antiguos derechos.

Poco a poco el miedo empezaba a disiparse; así puede observarse en este testimonio de Daniel sobre la asamblea que a inicios de 1984 se realizó en la fábrica en la cual trabajaba, donde se conformó su primera comisión interna: “...cuando estamos en la puerta sale el capataz, la ingeniera de fábrica y el gerente, salen a intimidar, a que no se realice la asamblea. Yo hablo y digo que hagamos la asamblea compañeros, no tengamos miedo, estamos en democracia... y de ahí sale la comisión interna...". ${ }^{47}$ Esto también lo destaca René: “...nos habíamos reunido pero no teníamos todavía la cosa esa de salir a la calle, darnos a conocer, porque había mucho miedo... Fuimos y les leímos la constitución a los compañeros, el 14 bis, el derecho a la huelga, para que tengan un sustento de donde agarrarse. Esa tarde a las 6 se toma la fábrica”. ${ }^{48}$

Es evidente el rol de los militantes

46. "Así logramos sacar algunos delegados medio combativos que tampoco pudieron lograr ganar reclamos porque la UOCRA te quedaba allá lejos y no acompañaba los reclamos de los delegados que no manejaba". Oscar, obrero de la construcción y militante político. Entrevista realizada en el café Touring Club, el 14/4/2012.

47. Daniel, entrevista..., Op. Cit.

48. René, entrevista..., Op. Cit. 
explicando al resto de los trabajadores las nuevas posibilidades de acción que el régimen constitucional les permitía. Y resaltamos que la capacidad de movilización que expresaban estos obreros parece poner en duda la idea de que emergían de una profunda derrota; más bien la amplia actividad política y sindical hacía observable el proceso de acumulación de experiencias que venían desarrollando a través de formas de resistencia y organización no públicas durante la dictadura. Es esa acumulación la que se comenzaba a expresar públicamente.

El papel de los militantes y la importancia de las experiencias previas, también lo destaca Oscar: "Fuimos analizando que en esa época se venían las elecciones de nuestro sindicato y la idea era recuperar el sindicato porque no nos estaba sirviendo... ahí apareció un compañero, que era Adrián, ${ }^{49}$ y ese compañero se sumó a colaborar. Y él fue un poco el que abrió la cabeza a los delegados, que si bien eran muy buenos compañeros no sabían nada de generar el reclamo, y cómo ganarlo ¿no? No había una experiencia de lucha. Y este compañero que venía del cordobazo y de otras cosas de afuera, volcó acá toda su experiencia de lucha... nos enseñó". ${ }^{50}$

La dictadura no parece haber atacado las experiencias previas de esta clase, porque se trataba de una clase en formación que estaba dando sus primeros pasos de organización. Este marco es distinto al que puede encontrarse en otros lugares del país; por ello la dinámica regional nos permite complejizar el debate desde una mirada que no homogeneiza a la clase, apuntando a comprender las

49. Adrián fue un militante del Partido Obrero (PO) nacido en Trelew en el seno de una familia tradicional de la región. Su politización se desarrolló en Córdoba donde había estudiado y se integró al PO.

50. Oscar, obrero de la construcción y militante político. Entrevista..., Op. Cit. especificidades de sus diversas fracciones $\mathrm{y}$ capas.

En la AOT, la UOM (Unión Obrera Metalúrgica) y la UOCRA (Unión de Obreros de la Construcción $)^{51}$ se comenzó a debatir la conformación de listas que plantearan la disputa contra la conducción sindical. Las historias en la AOT y la UOM coincidieron: en la elección de 1985 ganaron listas que se definían como pluralistas y combativas, siendo reemplazadas por las anteriores conducciones en la siguiente elección.

En la AOT se conformó la Agrupación Textil “1o de Mayo", que en 1985 logró desplazar a quién había sido secretario general durante la dictadura. Convergieron en su seno distintas expresiones políticas: grupos del peronismo (que encabezaron la lista), del PI, PC, MAS y PO. Un proceso similar se dio en la UOM: allí sectores del peronismo junto a expresiones de izquierda (ligadas al PC y al Partido Socialista Auténtico, PSA) lograron derrotar a la lista de la conducción tradicional. ${ }^{52}$

En los casos en que las listas opositoras triunfaron, fueron procesos de importante movilización, que luego no se tradujeron en una transformación de los sindicatos. Si bien en los primeros años plantearon cambios hacia una mayor democracia interna y presencia

51. La AOT y la UOM eran los sindicatos más poderosos de Trelew y Madryn, respectivamente, por tratarse de los gremios que representaban a los trabajadores de las ramas subsidiadas por los proyectos de polos de desarrollo. También la UOCRA tenía un rol central, ya que la realización de nuevas obras era constante en ese período. Esto se modificaría en los ' 90 , cuando los sindicatos de comercio y servicios pasarían a tener mayor peso.

52. Encabezada por Vicente Jara, quién luego recupera el gremio y fue hasta el 2011 dirigente de la UOM. La lista opositora se denominaba "Rafael Uribe", nombre de un militante obrero de ALUAR que había muerto pocos meses antes de la elección de 1985. 
en las calles, de a poco las nuevas direcciones se fueron apartando de ese modelo. Dentro de la UOCRA, la elección no pudo ganarse, en medio de denuncias de fraude de la Lista Naranja que fuera impulsada por militantes ligados al PO. La nueva conducción de la AOT se fue adaptando a las características de la dirigencia nacional. En las entrevistas, los trabajadores destacaron la importancia que tuvo la presión nacional, a través del ahogo financiero cuando la regional "osaba" asumir posturas propias que propusieran medidas en las calles, contraviniendo la línea negociadora de la dirección nacional. El proyecto amplio y diverso de la "10 de mayo" se fracturó, conformándose agrupaciones identificadas con los diversos partidos políticos que tenían presencia entre los textiles. ${ }^{53}$

La experiencia de ganar la conducción regional de la UOM tampoco se consolidó como un proyecto sindical alternativo. No se logró construir una estrategia obrera distinta a la que representaba la dirección nacional de la UOM. La estructura centralizada impedía el manejo de fondos, y los intentos por construir un mayor nivel de autonomía no consiguieron plasmarse en la realidad. En las siguientes elecciones este frente se rompió, posibilitando la victoria de la línea que representaba a la conducción nacional.

Para nosotros, por sobre las cuestiones organizativas y formales, el límite mayor que encontraron estos intentos de construcción de un sindicalismo alternativo al dominante, fue el nivel de conciencia que seguían expresando las bases, y del cual esas direcciones eran expresión. No se consiguió romper con los límites de la perspectiva corporativa de los reclamos, y eso impidió articular un proyecto

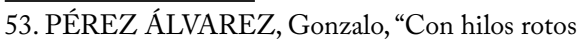
vamos tejiendo otra historia" Lucha y experiencia obrera en el parque textil de Trelew", en Sociohistórica FAHCEUNLP, La Plata, 2011, No 27, pp. 13-39. alternativo, que diera sustento a otro tipo de estrategia. Por eso, no consiguieron generar procesos de unidad con otros colectivos de trabajadores y menos aún pudieron plantearse una lucha en términos más amplios y sostener la posibilidad de dar una disputa en el plano político. Allí se hicieron visibles los límites de la forma sindical para posibilitar que los trabajadores realicen una verdadera ruptura contra su situación de subalternización política y económica.

Hacia fines de los años '80, comenzaba a surgir una mayor conflictividad en la región. Esto se hacía evidente en el parque textil de Trelew, hasta allí caracterizado por los escasos conflictos. Los trabajadores de la región se encontraban ante un nuevo marco social. Su historia de luchas pasaba por el reclamo de mejores condiciones laborales y aumento salarial; pero no tenían herramientas para saber cómo actuar ante una situación donde las empresas ya no les querían comprar su fuerza de trabajo. No se trataba de pelear por mejoras en el marco del mismo proyecto de los sectores dominantes: ahora necesitaban enfrentarse con el proyecto que desde el poder se les imponía. Era necesario construir uno alternativo y para ello no alcanzaba con una conciencia limitada al reclamo corporativo. El programa de la mayoría de los trabajadores dejaba la lucha circunscripta a cada fracción obrera, $y$ en ese círculo sus intereses parecían igualarse con los de sus patrones: la posibilidad de seguir trabajando residía en que a "sus" patrones les fuera bien. La conclusión se presentaba como simple y lineal: había que defender a las patronales para mantener las fuentes de trabajo. Pero además, se encontraron ante esa situación sin confianza en sus herramientas de organización y lucha. Las experiencias fallidas de intentar forjar un nuevo modelo sindical dejaron como mayor fracaso el no conseguir modificar el rol de esos sindicatos. Desde una relación de fuerzas que hacía difícil 
otro resultado, las conducciones no pudieron, o no quisieron, romper con esa búsqueda de acuerdos con las patronales.

\section{La organización política de los trabajadores}

Así como se reflejó en lo sindical, el regreso al régimen constitucional también generó un fuerte impulso a la actividad específicamente política-partidaria de los trabajadores. Se expresó el activismo de diversos núcleos obreros para intentar construir opciones partidarias que reivindicaran sus derechos y se afincaran en la clase trabajadora. El PC era el partido de izquierda con mayor tradición en la región. Sin embargo, hacia los años ' 80 había perdido algo de su influencia ante el desarrollo de nuevas organizaciones de izquierda. Con el regreso al régimen constitucional logró un importante nivel de inserción en el parque industrial y varios simpatizantes en ALUAR. La conformación del MAS se realizó hacia 1983, a partir de algunos cuadros del morenismo ${ }^{54}$ que habían llegado a la región durante la dictadura como forma de "exilio interno". Esta organización consiguió un rápido desarrollo en docentes y estatales, y construyó algún nivel de apoyo entre los textiles. A partir de 1988, comenzaron rupturas de importancia en esa organización a nivel nacional, proceso que impactó en la región. Hacia 1990 y 1991, la crisis del MAS se hizo evidente, llevando prácticamente a su disolución en la región que estudiamos. Una experiencia interesante fue el desarrollo del PO. A partir de la relación que estableció un cuadro de esta organización con un grupo de trabajadores de la construcción, se dio un proceso de politización que llevó a la formación del $\mathrm{PO}$ en la provincia, y su presentación a las elecciones de 1987. Para nuestros entrevistados la formulación de "partido obrero" aparece

54. Corriente del trotskismo argentino, nucleada alrededor de su principal dirigente, Nahuel Moreno. como una definición de clase, y no como de identidad política; ${ }^{55}$ o sea la construcción de ese partido tenía relación con el adjetivo que lo definía (la identidad "obrera") más que con la identidad partidaria. Su presentación a elecciones sostuvo un nivel de actividad que llegó hasta 1991. Luego el enfrentamiento del dirigente local con la conducción nacional y el alejamiento de varios obreros que habían conformado el núcleo inicial, dieron un punto final al proceso. El PI tuvo desarrollo a partir del regreso al régimen constitucional. $\mathrm{Si}$ bien su dirección era de sectores medios consiguió una importante inserción entre los textiles. ${ }^{56}$ La elección presidencial de 1989 fue el punto de quiebre, a partir de que varios de sus cuadros obreros se retiraron de la organización en contra del apoyo que el PI otorgó a la candidatura presidencial de Carlos Menem. ${ }^{57}$ La construcción del PSA también tiene una historia en la región que proviene de los años '70. Tanto el PI como el PSA eran organizaciones partidarias que no planteaban una perspectiva clasista pero, para los años '80 en la región, tenían fuerte influencia entre

55. Al caer derrotados en las elecciones de la UOCRA se plantea el debate acerca de cómo continuar con su proyecto. Así describe Oscar el proceso: "era la gran necesidad de conformar un partido, porque ya habíamos visto que era imposible recuperar el sindicato por la plata que le daban desde el Estado, desde el ministerio de trabajo... y bueno por la burocracia de mierda. Entonces a la gente le parecía bien eso de armar un partido... y se terminó armando un partido obrero." Claramente Oscar nos habla de la conformación de "un" partido obrero y no de "el" Partido Obrero.

56. La diferencia entre el afluente obrero y los demás sectores del PI son claros para Miguel: “...muchos del PI, militaban acá, sentados acá y no conocían más allá de la Colombia”. La calle Colombia es el límite del centro urbano de Trelew, donde empiezan los barrios populares. La referencia a "acâ" es por el lugar en que se realizó la entrevista, un céntrico café de la ciudad.

57. Así lo describe Miguel: "Yo era convencional nacional del PI, la convención vota en contra de la alianza con Menem y el PI va con Menem, ¿más clarito?”. 
los trabajadores y construyeron la mayoría de sus alianzas sindicales con otros grupos de izquierda. El PSA tenía un peso relevante dentro de la conducción de la UOM.

Hemos visto el impulso que estos procesos de organización sindical y política desarrollaron a partir de 1983. Sin embargo, esto rápidamente comenzó a cambiar; desde mediados de los '80 empezaron a expresarse diversos rasgos que mostraban el fin de este impulso. Y hacia fines de la década ya era claro que estaba gestándose una bisagra histórica, que impactaría sobre los trabajadores, sus organizaciones y sus luchas. Especialmente el año 1989 aparece como un punto de quiebre. La hiperinflación, la revuelta y los saqueos, y la asunción de Menem, generaron las condiciones de realización hegemónica del neoliberalismo. ${ }^{58}$ Los trabajadores vieron arrasadas gran parte de sus conquistas y sus organizaciones, tanto las sindicales como las partidarias. En la región se aceleró la caída del proyecto de polos de desarrollo: hubo gran cantidad de despidos entre los textiles y en las demás actividades vinculadas al proyecto de industrialización subsidiada. Fue evidente la profunda crisis que se desató en el parque industrial y en el resto de las pequeñas y medianas empresas.

También 1989 fue un punto de quiebre para las construcciones sindicales de los trabajadores; la derrota, ahora sí, se presentaba como una realidad. Casi todos los delegados de fábrica, opositores a la conducción sindical, comenzaron a ser despedidos, pese a contar con fueros legales que deberían haber impedido dicha resolución.

En ese marco, las construcciones políticas que habían conformado los trabajadores fueron

58. DONAIRE, Ricardo y LASCANO, Verónica, Movimiento obrero e hiperinflación, PIMSA DT, Buenos Aires, 2002, № 36. arrasadas. Este rasgo muestra sus límites y la incapacidad que tuvieron para plantear un proyecto alternativo ante la imposición del neoliberalismo. Pero a la vez, esa caída, en el marco de la derrota que estaba sufriendo el conjunto de la clase, demostraba que esas construcciones eran un producto genuino de la experiencia obrera y del avance de su politización en el marco del ciclo de luchas. Cuando ese ciclo fue interrumpido, estas organizaciones partidarias fueron las primeras que sufrieron el golpe. Es una evidente respuesta ante aquellas miradas que ven a los partidos de izquierda como ajenos a la clase o como "infiltrados" en las luchas sociales.

\section{Acerca de derrotas y de diversos derroteros}

La intención de este artículo fue avanzar en la problematización acerca de los hitos ${ }^{59}$ en la historia de la clase obrera regional y la clase obrera argentina. Sabemos que en todo proceso histórico existe un conjunto de rupturas y continuidades, que nunca son tajantes, pero que pueden permitirnos explicar y encontrar los momentos de cambio en las correlaciones de fuerzas sociales en nuestro país y en cada una de sus regiones. Como vimos el estudio de una dinámica "regional" no significa ver sólo una parte del proceso. Las regiones son a su vez constitutivas del todo, y en ellas las relaciones de fuerzas generales adoptan formas y características diversas, que a su vez influyen en cómo se transforman las relaciones de fuerzas a nivel general.

En este caso, hemos avanzado tras una hipótesis: la última dictadura cívico-militar no significó una profunda derrota para el conjunto

59. Utilizamos la noción de hito para referirnos a los momentos en los cuales las distintas fracciones de clase ven modificadas sus correlaciones de fuerzas. 
de la clase obrera que se venía conformando en el noreste de Chubut en torno al programa de industrialización subsidiada. Dicho de otra manera, la noción de "derrota" no resulta operativa para explicar la dinámica con la cual vemos actuar a la clase, tanto durante la dictadura como ante el regreso al régimen constitucional. Lejos de encontrarnos con una clase débil, vemos un conjunto de trabajadores dinámicos, con propuestas sindicales y políticas, y con una actitud de ofensiva para conquistar nuevos derechos sociales y laborales.

Si bien la problemática explorada tiene vínculos con el cuestionamiento que Pozzi y Schneider realizan a la noción de derrota, no hay una conexión absoluta entre ambas lecturas. Para ellos la dictadura no significó un cambio profundo en la correlación de fuerzas sociales para la clase obrera a nivel nacional, sino un paso más en una larga etapa de pérdida de posiciones: “...distintos informantes marcaron que si bien 1976 fue duro, fue un momento más dentro de una etapa negra que se inauguró en $1955 " .{ }^{60}$

No es esa hipótesis la que creemos corroborada aquí. En nuestro trabajo, se pone de manifiesto que la clase obrera argentina se compone de múltiples fracciones, y que una de esas complejidades clave es la regional. En cada región la clase se conforma de diferentes maneras y sufre distintos procesos. Para el noreste de Chubut, hay dos elementos claves que explican por qué la clase no vivió durante la dictadura un cambio negativo en la correlación de fuerzas sociales. El primero es que estábamos ante una clase en formación. La clase obrera de la región no sufrió una derrota durante la dictadura, ya que no había una tradición obrera que se apuntara a destruir. No existían

60. POZZI, Pablo y SCHNEIDER, Alejandro, Combatiendo el capital: Crisis y Recomposición de la clase obrera argentina (1985-1993), El Bloque Editorial, Buenos Aires, 1994, p. 20. organizaciones poderosas o partidos políticos de la clase, conformados y con capacidad de acción, que se debieran atacar. De hecho, es durante ese período cuando se conformaron las primeras experiencias significativas de autoorganización, especialmente entre los trabajadores privados. El segundo elemento, evidentemente conectado con el anterior, es que la clase dominante de la región necesitaba que esa clase obrera se conformara, creciera y que asegurara la provisión de fuerza de trabajo capacitada y disponible para las necesidades crecientes que planteaba un parque industrial en desarrollo. Precisaban trabajadores y por ello estaban dispuestos, como puede verse en el caso de la migración chilena, hasta a aceptar la presencia de obreros politizados. Esto no implica que no hubiese persecuciones y despidos. Pero aún los obreros despedidos por su activismo en una fábrica rápidamente volvían a conseguir trabajo en otra empresa.

Este elemento es clave para comprender la especificidad del desarrollo capitalista en Patagonia durante los años '70, donde se atravesaba un momento diferente al que ya se vivía a nivel nacional. Por ello, para la clase dominante eran necesarias distintas políticas hacia la clase obrera: mientras en la mayoría de las regiones del país se expulsaba a los trabajadores de sus antiguos territorios sociales (en el marco del avance del dominio del capital financiero), aquí se los recibía y se los incorporaba, en una perspectiva cercana a la fase de hegemonía del capital industrial. ${ }^{61}$ De tal modo, es posible que pueda registrarse una "derrota" de la clase en el plano nacional pero que esto no necesariamente se traduzca de la misma manera en cada región. Esto

61. Sobre las formas que toma el desarrollo capitalista en la región durante los '70 ver PÉREZ ÁLVAREZ, Gonzalo, "Una discusión con el concepto de "des industrialización" desde el caso del noreste de Chubut", en Revista de Estudios Marítimos y Sociales, GESMarUNMdP, Mar del Plata, 2013, No5, pp. 175-185. 
comenzaría a cambiar hacia mediados de los '80. En los inicios de los años'90, la hegemonía del capital financiero sobre todo el país era ya evidente. Se unificó la política hacia la clase obrera y se avanzó de manera uniforme sobre sus derechos sociales y laborales. Entonces sí, la derrota de la clase obrera se presentó como una realidad en todo el territorio nacional.

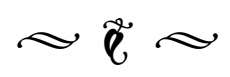

Recibido: $26 / 10 / 2013$

Aceptado: 11/03/2014

Publicado: 31/07/2015 